\title{
Editorial
}

\section{Trans-Pacific Minor Visions in Japanese Diasporic Art}

\author{
Yasuko Takezawa \\ Kyoto University, Kyoto, Japan \\ takezawa.yasuko.2u@kyoto-u.jp \\ Laura Kina \\ DePaul University, Chicago, IL, USA \\ lkinaaro@depaul.edu
}

This special issue of ADVA Journal sheds light on new dimensions of Japanese diasporic art to reflect the encounters of Japanese diaspora artists with other transmigrants and/or minoritized and marginalized peoples. We echo Viet Thanh Nguyen and Janet Hoskins' approach to defining "Trans-Pacific" as not a particular geographical region, but as "spaces of interaction." In this spirit, we have sought to feature horizontal encounters, networks, and alliances, and foster conversations between minoritized and marginalized peoples and "othered" Japanese and Japanese diasporic artists and scholars, all of whom have complex identities, multiple perspectives, and transcended borders.

There has been a wealth of recent scholarship on Japanese American modern art, including book publications such as Tom Wolf's The Artistic Journey of Yasuo Kuniyoshi (2015) and Shipu Wang's The Other American Moderns: Matsura, Ishigaki, Noda, Hayakawa (2017). Moreover, Japanese diasporic artists such as Isamu Noguchi, Chiura Obata, and Ruth Asawa are widely recognized

1 Janet Alison Hoskins and Viet Thanh Nguyen eds., Transpacific Studies: Framing an Emerging Field (Honolulu: University of Hawai'i Press, 2014), 7. 
in the canon of Western art history. The post-war years brought a new wave of Japanese avant-garde artists circulating in the diaspora (such as Yoko Ono, Yayoi Kusama, and Shigeko Kubota) as well as the international influence of Japanese art movements such as Gutai and Butoh that continue to inform contemporary art practice. This issue, however, intentionally focuses on subjects that have previously been forgotten or as Lisa Lowe's describes, "cast as failed or irrelevant because they do not produce 'value' legible within modern classifications." ${ }^{2}$ By using a Trans-Pacific studies framework, we intend to reexamine and re-evaluate transnational and inter-group relationships and networks to uncover lesser-known stories. ${ }^{3}$

The Japanese diaspora have empathized with other transnational immigrants and lived shoulder to shoulder, often in solidarity, with other minoritized people. ${ }^{4}$ Civil rights and labour rights histories are rich with examples Japanese American activism for immigration rights and support of Muslim communities being among them. These lived experiences have created hybrid worlds that have allowed Japanese diasporic artists to produce new styles of art, which did not previously exist either in their homelands or the societies that they now inhabit. These art forms emerged as the result of horizontal relationships with other immigrants and minoritized people.

This special issue also focuses on the diversity and complexity of Japanese diasporic communities in the Trans-Pacific. Within the minoritized Japanese diaspora, Okinawans and Koreans, for example, have been particularly discriminated against due to Japanese prejudices and histories of war and colonization. A suspicion of, and frustration with, gender roles and inequality are major themes that women artists have been dealing with. This multilayeredness is clearly evident in the articles that follow.

The issue thus explores and expands on influential texts in Trans-Pacific studies that include the anthologies Minor Transnationalism (2005) edited by

2 Lisa Lowe, Intimacies of Four Continents (Durham, NC: Duke University Press, 2015), 17-18.

3 Given space limitations, this special issue focuses on Japanese American, Nippo-Brazilian (Japanese Brazilian), Okinawan diasporic, and Zainichi Korean (Japan-based Korean) artists. There are of course Japanese diasporic artists working elsewhere, including across Latin America (for example, Peru), the Caribbean, Canada, Africa, Asia, and the Pacific.

4 We recognize the complex racialization of the Japanese diaspora. For example, on one hand, in the historically Black vs. white racial hierarchy of the United States, Japanese diaspora have been viewed as forever foreign, used as racial wedges, and were forcibly incarcerated during World War II. On the other hand, alongside histories of solidarities with other minoritized and transmigrant communities, the Japanese diaspora have also been complicit in antiBlackness, settler colonialism, white supremacy, and racism against other Asians. 
Françoise Lionnet and Shu-mei Shih, The Trans-Pacific Imagination: Rethinking Boundary, Culture, and Society (2012) edited by Naoki Sakai and Joo Yoo Hyon, and Transpacific Studies: Framing an Emerging Field (2014) edited by Janet Alison Hoskins and Viet Thanh Nguyen, as well as exhibitions, and the book-length publications that accompany them, such as Transpacific Borderlands: The Art of Japanese Diaspora in Lima, Los Angeles, Mexico City, and São Paulo (2017) at the Japanese American National Museum in Los Angeles, and symposium proceedings such as Global Art and Diasporic Art in Japan and Asia (2018), edited by Kotaro Shimada and others, published by the Mori Art Museum in Tokyo.

Pointing out the inefficiency of "the emphasis on the major/resistant mode of cultural practices," Lionnet and Shih argue that, "what is lacking in the binary model of above-and-below [is] an awareness and recognition of the creative interventions that networks of minoritized cultures produce within and across national boundaries." ${ }^{5}$ We also recognize the hegemony of the United States over the Trans-Pacific as well as its "transpacific complicity": "the United States as an area should not be definitely separated from East Asia; [it] is an integral part of things happening in East Asia." 6 With the rise of nationalism and xenophobic anti-immigrant and racist discourse in the US and Japan, and the current global upending of Cold War configurations and alliances under the Trump regime, it is urgent that Asian American studies not be limited to assumptions of delimited hemispheric or national boundaries.

The five articles, two Spotlights, and two Perspectives essays compiled here are a direct outgrowth of the international one-day symposium, "Trans-Pacific Japanese Diaspora Art: Encounters and Envisions of Minor-Transnationalism," which took place in Tokyo in December 2018 as a Kyoto University Zinbunken (Institute for Research in the Humanities) Academy organized in cooperation with the Mori Art Museum, to present scholarship on Japanese American, ${ }^{7}$

5 Françoise Lionnet and Shu-mei Shih, "Introduction: Thinking through the Minor, Transnationally," Minor Transnationalism, edited by Françoise Lionnet and Shu-mei Shih (Durham: Duke University Press, 2005), 7 .

6 Lionnet and Shih, "Preface," Minor Transnationalism, vii.

7 According to the 2010 US Census, the 2017 estimated Asian population of Japanese heritage alone, as well as in combination with one or more other detailed Asian group or another race(s), was 1.5 million. "Asian-American and Pacific Island Heritage Month: May 2019," 8 May 2019, accessed 1 March 2020, https://www.census.gov/newsroom/facts-for-features/2019/ asian-american-pacific-islander.html. 
Nippo-Brazilian, ${ }^{8}$ Okinawan, ${ }^{9}$ and Zainichi Korean ${ }^{10}$ artists. ${ }^{11}$ Following the Tokyo symposium, we met with the featured speakers - Rebecca Jennison, Megumi Kitahara, Valerie Matsumoto, Michiko Okano, and Yong Soon Min - to develop our special issue. All of our papers involved primary research conducted through original artist interviews or, in the case of Matsumoto and Kitahara's articles - interviews with descendants of the artist and original findings from their archival research. Nguyen and Hoskin's formulation of "spaces of interaction" was a theme that reoccurred across our papers, and we distilled the content of our presentations into four key ideas: trans (trans-disciplinary, Trans-Pacific, and transnational), negotiation, "diverse/multiple Japans," and contact zones. This issue extends our conversation to include both an interview with Japanese American artist Michael Sakamoto and dedicated artist pages by Jave Yoshimoto.

Rebecca Jennison's article, "Contact Zones and Liminal Spaces in Okinawan and Zainichi Contemporary Art," opens this issue by focusing on inter-Asian

8 Of the $211,118,775$ population of Brazil, the estimate of Brazilians of Japanese ancestry, or Nippo-Brazilians, is between 1.4-1.5 million. According to The Japanese Consulate in São Paulo, the last actual statistic from 1998 was 83.803 people. They estimate that there are currently 1.5 million Nippo-Brazilians, with the majority living in São Paulo, Paraná, Mato Grosso do Sul, and Pará. "Relações Bilaterais," Consulado Geral do Japão em São Paulo, accessed 1 March 2020, https://www.sp.br.emb-japan.go.jp/pt/bilateral/embaixada.htm. The Centro de Estudos Nipo-brasileiros (Center of Japanese Brazilian Studies) estimates 1.4 million Japanese Brazilians, or less than $1 \%$ of Brazilian population. "Os imigrantes japoneses e suas famílias no Brasil," Centro de Estudos Nipo-brasileiros, accessed 1 March 2020, https://cenb.org.br/articles/display_pt/207.

9 According to the Worldwide Uchina Network, it is estimated that there are 400,00o people of Okinawan descent across the world. World Wide Uchina Network, accessed 1 March 2020, https://wun.jp/en/wun.

10 According to the Japanese Ministry of Justice, as of June, 2019, the number of Korean nationals was 451,543 , including recent immigrants from South Korea. These statistics exclude what Mindan, a major Zainichi organization, estimates to be approximately 360,000 people of Korean descent who have already been naturalized. "Zainichi community in Japan," Mindan. (n.d.). accessed 1 March, 2020, https://www.mindan.org/syakai.php; "Number of foreign residents in Japan as of June 2019," Ministry of Justice, Japan. (25 October 2019), accessed 1 March, 2020, https://www.moj.go.jp/nyuukokukanri/kouhou/ nyuukokukanrio4_00083.html.

11 Simultaneous translation into Japanese and English were provided during the "TransPacific Japanese Diaspora Art" symposium on 8 December 2018. Scholars based in various locations who gave feature presentations were as follows: from the US, Laura Kina, Valerie Matsumoto, and Yong Soon Min; from Brazil, Michiko Okano; and, already in Japan, Rebecca Jennison, Megumi Kitahara, and Yasuko Takezawa. There were also five Japanbased US scholars and Japanese scholars who served as commentators: Mami Kataoka, Lon Kurashige, Reiko Kokatsu, Gayle Sato, and Izumi Nakajima. Kataoka and Kurashige's contributions are included in this issue. 
dialogues, the complexity of transborder migrations, and "entangled histories" between Okinawa, Jeju Island, and Japan in the interdisciplinary works of Okinawan artist Chikako Yamashiro and Zainichi Korean artists Soni Kum and Haji Oh. ${ }^{12}$ Jennison examines ways in which these artists use "metaphors, materials, techniques and narrative practices" to navigate liminal spaces such as the past and present, living and dead, forgotten and remembered, and physical borders such as the fence line or border between land and sea on US military bases in Okinawa. The article returns to Marie Louise Pratt's concept of "contact zones" to analyse Oh's Grandmother Island Project (2017), Kum's vegetation (2010) and Morning Dew (2019-20), and Yamashiro's Mud Man (2016) and Chinbin Western (2019).

Negotiation of post-war US-Japan power relations and a social and political critique of post-9/11 US is explored in Yasuko Takezawa's article "Major and Minor Transnationalism in Yoko Inoue's Art." Originally from Kyoto, Inoue is a New York-based multi-media conceptual artist who works in ceramics, installation, and performance art. Based on a series of interviews she conducted with Inoue, Takezawa examines the artist's inspirations and connections with other transmigrants and minorities, including the Jamaican sculptor Nari Ward, Latin American street vendors on New York's Canal Street, and a Navajo Chief. Specifically, the article examines Inoue's ten-year project Transmigration of the SOLD, her 2017 SFAI14o Hiroshima and Nagasaki cake performance at the Santa Fe Art Institute, New Mexico, and the 2017 Tea Taste Democracy and Upside-Down Objects at SPACES gallery in Cleveland.

Diverse Japans are also explored in Laura Kina's "Ancestral Cartography: Trans-Pacific Interchanges and Okinawan Indigeneity." Scholar and visual artist Kina brings her own work into conversation with fellow Okinawan artists and activists to explore how Okinawan Indigenous identity is influenced by the Trans-Pacific interchanges between the Native Hawaiian sovereignty movement and Native American Indigeneity. The author interviewed Okinawan diaspora performance artist Denise Uyehara about her collaboration with Native American artists, including her 2012 Archipelago performance with Adam Cooper-Terán, her 2017 Ancestral Cartographic Rituals collaboration with the late James Luna, and her 2017 immersive theatre project Shooting Columbus collaboration with The Fifth World Collective. Kina also discusses her Sugar series of paintings about Hawaiian sugar plantations, and her

12 Oh's family migrated from Jeju Island to the Korean peninsula during the period of Japanese colonization. 
trilingual illustrated children's book Okinawan Princess: Da Legend of Hajichi Tattoos, written by Hawai'i Creole author Lee A. Tonouchi. ${ }^{13}$

Valerie Matsumoto's “A Living Artist with Open Eyes': the Transnational Journey of Mitsu Yashima" highlights the life and career of transnational political dissident, artist, and illustrator Mitsu Yashima (1908-1988). Yoshima was a proletarian rights activist in pre-war Japan, went on to oppose Japanese militarism in World War II, participated in the Women' Strike for Peace antiwar movement during the Vietnam War, and became a cultural worker and community builder in the 1970s through the Japantown Art \& Media Workshop in San Francisco. Matsumoto provides us with a feminist art historical perspective of minor transnationalism in Japanese diasporic art and illuminates a little-known first-generation story of involvement in the Asian American movement.

Megumi Kithara's "Transcending Borders in the Work of Fumie Taniguchi" introduces us to a Nihonga ("Japanese painting") artist who was well known in Japan in the 1930s for her paintings of "modern girls" and working women but later fell into obscurity when she immigrated to the US in 1955. Through archival research in both Japan and the US, and oral history interviews with Taniguchi's family members, Kitahara recovers Taniguchi's post-war life as an artist and writer for Nanka Bungei magazine - a Japanese literary journal based in Los Angeles. Kitahara's essay emphasizes the transborder nature of Taniguchi's practice across Japan and the US, from painting to writing, and the patriarchal challenges the artist faced along the way.

The deep biographical research informing Matsumoto and Kitahara's articles is also apparent in our two featured Spotlight contributions by Michiko Okano and Yong Soon Min -who make important gestures to begin filling the gap in art historical writing on Nippo-Brazilian and Zainichi artists respectively. Extensive studies and resources on these topics are scarce in the context of diasporic studies in Japanese modern and contemporary art.

Michiko Okano's Spotlight “Transnational Perspectives of Nippo-Brazilian Artists: Sachiko Koshikoku and Kenzi Shiokava" emphasizes the theme of diverse and multiple Japans and the transnational circulations of Nippo-Brazilian artists. Sachiko Koshikoku (1937-2019) was a post-war Japanese immigrant to Brazil whose colourful, geometric patterned, abstract paintings were heavily influenced by the hybrid aesthetics of Brazil's creolized culture. As Koshikoku sadly passed away in 2019, Okano's contribution documents one of the artist's last interviews in which she talks about her late work. Kenzi Shiokava (b. 1938)

13 Lee A. Tonouchi, Okinawan Princess: Da Legend of Hajichi Tattoos (Honolulu: Bess Press, 2019). 
is a second-generation Japanese Brazilian who moved to Los Angeles in 1964. His wooden and found object assemblages and totems are a confluence of influences from African American, Latin American, Native American, and Japanese art and cultural traditions and popular culture. Okano's Spotlight reminds us that to understand these artworks we have to go beyond a binary national boundary to look at complex networks of "multiple spatialities, temporalities, and cultures."

The theme of a diverse Japan in negotiation is further underscored in the Spotlight by our featured symposium keynote Yong Soon Min, "Zainichi Korean Artist Fung Sok Ro and Questions of Homeland." An internationally renowned Korean American artist and curator based in Los Angeles, Min shares with readers her father's connection to Japan as a student at Waseda University in Tokyo during World War II, providing an overview of the history of Koreans in Japan, who are known as Zainichi Koreans, or simply Zainichi (literally, in Japanese, "living in Japan"). This piece puts a spotlight on the life and work of a Zainichi sculptor Fung Sok Ro, who Min first met through her curatorial research in Japan for THERE: Sites of Korean Diaspora, an exhibition and symposium at the 2002 Gwangju Biennale. In his work and activism, Ro negotiates his identity coming from a family involved with the Chongryun organization who supported North Korea and his role as founding member of Areum Art Network (1999-2006) in Tokyo - a group of Zainichi Korean artists who view themselves as "independent of ideological allegiances to South or North Korea." Ro's work engages with themes of dislocation and cultural negotiation as he looks back at Korea's history while simultaneously offers a critique of living and working in postmodern Japan. Min looks at Ro's struggle for hybridized and complex representation that resists falling into the stereotypes of Zainichi Korean as either invisible or hypervisible essentialized subjects.

Two of the five commentaries are also included in ADVA's Perspectives section. Historian Lon Kurashige offers insights from the perspective of ethnic studies on ways in which several of the articles in the issue address the constructed nature of identity. Finally, Mami Kataoka, Director of the Mori Art Museum, one of the largest contemporary art museums in Japan, offers her insights on art museum and curatorial diversity practices in Japan, reminding us that the concept of the art museum was imported from the West into Japan in the 1930 s and only really came into fruition in the public sphere in the 1950s. Her Perspective piece asks, "How have Japanese diaspora artists been presented in the context of the activities of modern and contemporary art museums ever since?"

In addition, this issue features an interview and artist pages. Jonathan W. Marshall's interview with artist Michael Sakamoto explores his $2018 \mathrm{MuNK}$ 
series - a semi-autobiographical photographic series set in the Manzanar concentration camp in California. The series is modelled on the famous photobook Kamaitachi (1969), produced by Japanese photographer Hosoe Eikoh in collaboration with the founder of butoh dance, Hijikata Tatsumi Sakamoto, a Nikkei Yonsei (fourth generation Japanese American) interdisciplinary artistscholar-curator from Los Angeles, who merges butoh dance with hip-hop aesthetics and movements drawn from his experiences growing up in a diverse ethnic neighbourhood of East LA. Featured in the Artist Pages is work by Nebraska-based, Japan-born Chinese artist Jave Yoshimoto, who immigrated to the US when he was nine. In works such as his Humanitarian Crisis series, Yoshimoto focuses on the refugee crisis and ways in which the wars in Syria and Afghanistan continue to drive migrants through Turkey, with many making their way to the Lesvos Island in Greece (Yoshimoto was a volunteer in Lesvos in winter 2016). Yoshimoto's interest in other minoritized transmigrants is particularly fitting for this themed issue of ADVA.

As our symposium commentator Mami Kataoka argues, contemporary art has become an important field of study that facilitates a comprehensive process of learning about diverse historical worldviews and political, social, and religious diversity. Art, as a mode of communication that can often transcend the barriers of language, has the power to communicate these complex histories. We hope that this special issue, taking Japanese diaspora artists and their works as examples, will provide a new understanding of the ways in which transmigrants and minoritized people have developed diverse horizontal "minor transnational" relationships and alliances.

\section{Acknowledgements}

This journal issue is part of the larger project, "An Integrated Research into the Processes and Mechanisms of Racialization" led by Yasuko Takezawa, funded by the KAKenhi of the Japan Society of the Promotion of Science (JSPS), which includes the 2018 symposium in Tokyo as well as other seminars and meetings. We would like to thank Lyle De Souza, JSPS KAKENH I Researcher, for his assistance. We are particularly grateful to the co-editors of the ADVA journal, Alice Ming Wai Jim and Alexandra Chang, for their support and careful editorial attention.

\section{Yasuko Takezawa (Co-Guest Editor)}

is Professor of Anthropology/Sociology, Institute for Research in the Humanities, Kyoto University. She is co-editor of Trans-Pacific Japanese American Studies: Conversations on Race and Racializations (with Gary Y. Okihiro, University of Hawai'i Press, 2016), 
editor of Racial Representations in Asia (Kyoto University Press, 2011), and author of Breaking the Silence: Redress and Japanese American Ethnicity (Cornell University Press, 1995). Her fields of interest include race/ethnicity, immigration, and social categorization.

\section{Laura Kina (Co-Guest Editor)}

is Vincent de Paul Professor of The Art School (formerly the Department of Art, Media, \& Design) and Director of Critical Ethnic Studies at DePaul University. Kina is co-editor of Queering Contemporary Asian American Art (with Jan Christian Bernabe, University of Washington Press, 2017) and War Baby/Love Child: Mixed Race Asian American Art (with Wei Ming Dariotis, University of Washington Press, 2013). Her research focuses on Asian American art, mixed-race, and Okinawan identity.

\section{References}

Anderson, Emily, ed. Transpacific Borderlands: The Art of Japanese Diaspora in Lima, Los Angeles, Mexico City, and São Paulo. Exhibition catalogue. Los Angeles: Japanese American National Museum, 2018.

"Asian-American and Pacific Island Heritage Month: May 2019." 8 May, 2019. Accessed 1 March, 2020. https://www.census.gov/newsroom/facts-for-features/2019/asianamerican-pacific-islander.html.

Hoskins, Janet Alison, Viet Thanh Nguyen, eds. Transpacific Studies: Framing an Emerging Field. Honolulu: University of Hawai'i Press, 2014.

Lionnet, Françoise and Shu-mei Shih, eds. "Introduction." Minor Transnationalism, edited by Françoise Lionnet and Shu-mei Shih, 1-23. Durham: Duke University Press, 2005.

Lowe, Lisa. Intimacies of Four Continents. Durham, NC: Duke University Press, 2015.

"Number of foreign residents in Japan as of June 2019." Ministry of Justice, Japan. (25 October, 2019). Accessed 1 March, 2020. https://www.moj.go.jp/nyuukokukanri/ kouhou/nyuukokukanrio4_ooo83.html.

"Os imigrantes japoneses e suas famílias no Brasil." Centro de Estudos Nipo-brasileiros. Accessed 1 March, 2020. https://cenb.org.br/articles/display_pt/207.

"Relações Bilaterais." Consulado Geral do Japão em São Paulo. Accessed 1 March, 2020. https://www.sp.br.emb-japan.go.jp/pt/bilateral/embaixada.htm.

Sakai, Naoki and Joo Yoo Hyon, eds. The Trans-Pacific Imagination: Rethinking Boundary, Culture, and Society. New Jersey: World Scientific, 2012.

Shimada, Kotaro, and Michiko Akiba, eds. MAM Documents oo2: Global Art and Diasporic Art in Japan and Asia. Tokyo: Mori Museum, 2016.

Tonouchi, Lee A. Okinawan Princess: Da Legend of Hajichi Tattoos. Honolulu: Bess Press, 2019. 
Wang, Shipu. The Other American Moderns: Matsura, Ishigaki, Noda, Hayakawa. Pennsylvania: Penn State, 2017.

Wolf, Tom. The Artistic Journey of Yasuo Kuniyoshi. Washington DC: Smithsonian, 2015. World Wide Uchina Network. Accessed 1 March, 2020. https://wun.jp/en/wun.

"Zainichi community in Japan." Mindan. (n.d.). Accessed 1 March, 2020, https://www .mindan.org/syakai.php. 